\title{
"Improvisation" in Corporations and Creative Music: What Are We Really Talking About?
}

\section{Scott Thomson}

In December 2011 I was invited to speak at Making the Changes: Ethics and the Improvising Business, a conference at the University of Guelph. I spoke as a member of the musicians' panel, which was part of the second half of the day-long proceedings that featured primarily presentations by management studies researchers and corporate managers. Prior to the conference, I had little knowledge of the role of improvisation in business management contexts or in the discourse of management studies. So, in an effort to make connections between business practices and my work as a musician and music presenter-connections that the conference seemed designed to help forge-l opted not to prepare my presentation and, instead, to reflect on and respond freely to what others said prior to our panel.

This essay is largely an anecdotal recollection of what I thought and felt that day, though l've taken the opportunity to flesh out some of my ideas in the space that this forum affords. I made no notes at the conference, so what's here is admittedly based on six-month-old memories. I trust that, though the veracity of some little details may be in question, I've captured the general flavour of the conference's problematics, at least as they are filtered through my own perspectives.

Throughout the morning of the conference, I heard several people speak about improvisation in corporate culture in both theoretical and practical ways. These perspectives included, for example, how improvisation in collaborative business management teams can generate creative and innovative solutions, and how improvisation in a public relations context can mitigate business crises. Interesting stuff, sure, but remarkably there was no real acknowledgement in these presentations of what the benefits of such improvisations are. Or, more likely, the benefit is axiomatic in a corporate or management studies context and need not be spoken: profit.

Though it may be tacitly understood in their discourse, the omission of the specifically goal-oriented nature of improvisation in corporate contexts demonstrated, to me, a dearth of critical engagement with what improvisation really is and does within different disciplines and in everyday life. As I listened, one particular question kept entering my mind: If "good" improvisation in a business management context is that which generates profit for the company and its shareholders, then how is it different from non-improvisational creative practices that achieve the same goal? Such definitions and distinctions were never addressed, as I recall. There was much lip-service to the value of creativity in general and improvisatory creativity in particular in contemporary business practices but, significantly, no discussion of what kinds of creativity are or are not sanctioned in corporate cultures, and why or by whom.

This was all quite foreign to someone like me who practices and thinks about improvisation as an open-ended creative process that is primarily collaborative in nature and, through such collaboration, demands the negotiation of the varied (and sometimes ineffable) aesthetic, social, political, economic, and spiritual goals, etc., of all involved. In my experience, defining a "good" improvisation-musical or otherwise-is never a simple, objective task. Considering this perspective, if I stick to the guiding principle that improvisation is primarily what improvisation does, then improvisation with a single goal is scarcely improvisation at all. In these presentations, the processual and collaborative nature that I recognize as a fundamental trait of improvisation was distorted and obscured as it became merely a means to a singular end. Profit, it seemed, was everything.

In a telling moment, speaker Chris MacDonald (Visiting Scholar at the Clarkson Centre for Business Ethics and Board Effectiveness, Rotman School of Management; Professor of Philosophy, St. Mary's University), discussed the improvisational acumen of a British Petroleum executive when speaking to the media during the early moments of the 2010 Deepwater Horizon oil-gush disaster in the Gulf of Mexico for which his company is responsible. MacDonald described the executive's performance for the ways it reassured shareholders and minimized BP's financial loss. The executive's improvisation, however, could not acknowledge, let alone reconcile, the varied desires of other stakeholders involved: those in the decimated seafood industry, those living in gulf communities whose health and quality of life are still compromised, those who seek better alternatives to fossil fuels, etc. ad nauseam.

In my own presentation, instead of dwelling on frankly upsetting examples like this one, I started from the premise that the speakers who had gone before me had focussed on the impact that improvisation (as they understand it) has on business practices. It seemed trenchant and fitting that I should discuss the impact that business practices have on improvisation (as I understand it), using my own experiences as a performer and presenter of creative improvised music as case examples. Throughout, the vital question to which I kept returning is, in different contexts, which kinds of improvisatory creativity are or are not sanctioned, and why and by whom? 
I began my discussion by pointing out how there is little economic motivation to play or present creative improvised music, and that practitioners, virtually without exception, are committed to the practice for other reasons. This was essentially a reiteration of points made by Ken Aldcroft during his excellent presentation to start the musicians' panel, ${ }^{1}$ and was directed to the conference participants from the corporate field who may have had no prior exposure to such music and musicians. I trust that there's no need to rehearse these points here.

From there, I described how I spent my formative years as an improvising trombonist in Toronto, where I became part of a dynamic collaborative network - a scene-of artists performing and presenting creative improvised music in public contexts. I described the infrastructure that has sustained this scene at different times, and emphasized how business-related pressures have influenced virtually every aspect of this infrastructure negatively.

In the early 2000s, the Toronto improvised music scene saw a burst of new activity through the organizational work of younger players, including Gordon Allen, Ronda Rindone, Mike Gennaro, Ken Aldcroft, and Joe Sorbara. For the most part, these activities-generally concert series-would take place in bars. Virtually all of these efforts resulted in versions of the same basic scenario: The bar-owner, having no particular interest in the oft-noisy creative improvised music being played, grew quickly dissatisfied with paltry attendance and bar-takes and would shut the series down, along with whatever promotional momentum the early concerts had generated.

As an alternative, some presenters like Ken and Joe sought a kind of refuge from such bottom-line business interests by presenting concerts in a Liberty Village loft called the Arraymusic Studio, named for the contemporary music ensemble for which it serves as a rehearsal space. So long as these presenters could cover the studio rental out of the door revenue, no business pressures would prevent them from presenting their concerts, no outside sanctioning power would deem the musicians' creativity to be unacceptable, as the bar-owners had.

However, a different order of business influence reared its head when, in 2007, the interests of condo developers dictated that the building that houses the Arraymusic Studio would be demolished, along with much of the affordable, flexible studio space in Toronto around that time. The announcement of Array's demolition coincided with an aggressive campaign of noise complaints-likely influenced by threats to property values of money-minded residential neighbours-against the Tranzac Club, the one bar in Toronto that had consistently supported noncommercial creative musicians.

It seemed like, in one fell swoop, the fragile infrastructure that sustained creative improvised music in Toronto would be wiped out by these related forces. It seemed like a crisis moment, and it motivated me to open Somewhere There, a venue exclusively for live creative music housed in a loft that had previously been a furniture store storage room. I ran this venue for three years until the summer of 2010. In its early days, it hosted four live music shows a week and, within a year, the number had increased to six or seven. Interested readers should note that I have written a more detailed history of and the philosophy that informed how I ran Somewhere There (Thomson xxx). It's pertinent to this discussion, however, to point out that, throughout my tenure as director, Somewhere There always ran a deficit, one that I covered through part-time teaching work. This condition was entirely justifiable because of other less intangible benefits-musical, creative, social ones - the space so clearly made possible.

A process of succession was underway during my last year as Somewhere There director, in which a collective of about a dozen colleagues-artists who share my wish to preserve and develop creative spaces that are noncommercial in nature-sought to take over its management and continue its programming. This process hit a harsh snag when, during lease negotiations with members of the collective, my former landlord announced that he was raising the rent by $20 \%$. When the new Somewhere There reps responded that the space had never generated enough revenue to cover the new sum, his arrogant reply was, "Well, you'll just have to be better businessmen than Scott is." It was the logic of the bar-owner shutting down the creative music series due to a lack of beer sales, but writ large. And it was a very depressing moment.

To their immense credit, the Somewhere There collective banded together and found a new space within a weekonly one scheduled show had to be canceled_and, though the new Sterling Road space is smaller than its Dufferin Road precursor, it still hosts creative music virtually every night and helps to sustain a scene in the process. ${ }^{2}$

Nevertheless, this essay clearly serves as a cautionary tale that bottom-line business practices (be they creative, improvisatory, or otherwise) will always threaten the survival of scenes of creative improvised music. Indeed, as I see it, it is a crucial application of artists' creativity to find solutions that confront or circumvent these threats. The goal, as I see it, is to restrict the power of those who function solely according to profit-based business practices to sanction or, more likely, not to sanction the creativity of improvising musicians. It is, obviously and depressingly, an increasingly difficult challenge. 
Evidently, experts in contemporary management studies and corporations want to discuss improvisation and its role in corporate organizations. The ethics of particularly egregious case studies aside, I guess that's fine. But if the discourses that were employed during the Making the Changes: Ethics and the Improvising Business conference are any indication, then it is clear that these experts are defining improvisation at best, narrowly, and at worst, inaccurately. Meanwhile, non-sanctioned kinds of improvisatory creativity ${ }^{3}$ are persistently at the mercy of the powerful forces that so-called "business improvisation" directly serves and in so uncritical a manner. When people from the fields of creative music and business talk about "improvisation," it's not merely that we are talking about fundamentally different things; we're talking about one version that works to marginalize and even to eliminate the other.

\section{Notes}

${ }^{1}$ The other member of the musicians' panel was Peter Johnston, and a version of his incisive and inspiring contribution is published in this issue as well.

${ }^{2}$ In January 2013, Somewhere There's Sterling Road location closed its doors after a sustained campaign of noise complaints by neighbours. Apparently, the relatively affordable rent of the space came with the compromise that its walls were shared by people who, like the bar owners and the landlord of the original Somewhere There, had no real sympathy for the music being played, and yet had control over whether or not it could be presented regularly-a fundamental dilemma in this debate, as I see it. The Somewhere There collective is searching for a new home at the time of this publication in the fall of 2013.

${ }^{3}$ By no means am I referring solely to creative improvised music here. It brings to mind-as topical example as I write in the spring of 2012 - the student protests in my new hometown of Montréal, where protesters employ a variety of improvisational tactics to defy and rally opposition to what many consider to be the government's oppressive, overly business-minded response.

\section{Works Cited}

Thomson, Scott. "One Musician Writes About Creative Music Venues in Toronto." People Get Ready: The Future of Jazz is Now. Ed. Ajay Heble and Rob Wallace. Durham, NC: Duke University Press, 2013. 175-83. Print. 